\title{
CALIDAD NUTRICIONAL DE LA PLANTA DE SORGO NEGRO FORRAJERO (Sorghum almum) PARA ALIMENTACIÓN ANIMAL ${ }^{1}$
}

\author{
Ana Lorena Amador ${ }^{2}$, Carlos Boschini²
}

\section{RESUMEN}

Calidad nutricional de la planta de sorgo negro forrajero (Sorghum almum) para alimentación animal. El propósito de este trabajo fue determinar el desarrollo fenológico de la planta y su calidad nutricional de la planta de sorgo en diferentes etapas de crecimiento. La siembra se realizó en la Estación experimental Alfredo Volio Mata, de la Universidad de Costa Rica. Se plantaron $18 \mathrm{~kg}$ del $88 \%$ de semilla germinable. El primer muestreo se realizó 24 días después de la emergencia, y luego cada 14 días hasta los 150 días. La producción de biomasa verde y seca en tallos, hojas y panoja fueron medidos a diferentes edades de crecimiento. Se midió la cantidad de materia seca, proteína cruda, cenizas totales, fibra neutro detergente y ácida, hemicelulosa, celulosa y lignina. Durante los primeros 52 días de crecimiento, la producción de hojas fue mayor que la del tallo. A los 57 días, el rendimiento de materia seca fue de $1395 \mathrm{~kg} / \mathrm{ha}$, compuesto en un $50 \%$ por hojas y otro $50 \%$ por tallos. La aparición de la panoja se inició a los 94 días, con un aporte inicial de $50 \mathrm{~kg} / \mathrm{ha}$ de materia seca y de $2588 \mathrm{~kg} / \mathrm{ha}$ a los 150 días. La concentración de materia seca en la hoja fue mayor que en el tallo, desde edades tempranas hasta los 136 días de crecimiento. El contenido de proteína cruda en la hoja fue siempre superior al mostrado en el tallo. En la hoja disminuyó de 28 a $16 \%$ conforme aumentó la edad de 38 a 150 días. En el mismo periodo la proteína cruda en el tallo disminuyó de 18 a $5 \%$ y en la planta total, la concentración pasó de 26 a $8 \%$. La fibra neutro detergente en hojas y tallos fue inferior a $60 \%$ en los primeros dos meses de crecimiento y valores superiores a $70 \%$ durante el restante periodo de crecimiento.

\section{ABSTRACT}

Nutritional quality of black sorghum (Sorghum almum) for fodder for animal feeding. The purpose of this study was to determine the phenological development and the nutritional quality of Sorghum almun during different growth stages. The seed was cultivated in the Alfredo Volio Mata Experimental Station of the University of Costa Rica. Eighteen $\mathrm{kg}$ of $88 \%$ germinal seed per hectare were planted. The first sample was taken 24 days after sprouting and every 14 days thereafter, up to 150 days. The production of biomass of the stems, leaves and ears of grain were measured and the amounts (content) of dry mater matter, crude protein, total ashes, neutral fiber and detergent acid, hemicellulosa, cellulose and lignin were determined. During the first 52 days of growth, the output of leaves was higher than that of stems. On the 57 th day, a yield of $1395 \mathrm{~kg}$ of dry matter per hectare, $50 \%$ leaves and $50 \%$ stems, was estimated. The ears of grain appeared after 94 days, contributing $50 \mathrm{~kg}$ per hectare of dry matter. The concentration of dry matter in the leaves was highest from the moment of sprouting to the 136th day. The content of crude protein in the leaves was always superior to that in the stems. In the leaves the crude protein diminished 16\%-28\% between the 38th and 150th day of growth. In the same period, the crude protein in the stem diminished 5\%-18\%, and in the whole plant $8 \%-26 \%$. The neutral fiber and detergent acid in the leaves and the stems were less than $60 \%$ during the first two months of growth and more than $70 \%$ in the latter period.

\section{INTRODUCCIÓN}

El sorgo negro forrajero fue descrito en Argentina en 1943, de donde parece se originó por un cruce espontáneo (Stevens, 1975; Simon, 1979). Se diseminó a diferentes países como Estados Unidos, Australia, Shi Lanka y Mozambique. Fue introducida a Costa Rica en 1949 desde Argentina y se comenzó a cultivar en las fincas lecheras de Cot, Tierra Blanca y Potrero Cerrado de la Provincia de Cartago. A partir de 1985 se comenzó a obtener resultados de investigación con esta espe- cie, especialmente de tipo agronómico (Corrales, 1986; Hernández, 1986; Alfaro, 1988; Villegas, 1990) y más recientemente, evaluaciones digestivas de aprovechamiento animal (Jiménez, 1995).

Durante décadas, las fincas lecheras cultivaron forrajes de corte, es el caso del pasto imperial (Axonopus scoparius) y Gigante (Pennisetum purpureum), los cuales fueron reemplazados por el pasto King Grass (Pennisetum hybridum), en la década del 70, debido a su alta producción de biomasa por hectárea.

\footnotetext{
1 Inscrito en la Vicerrectoría de Investigación, No. 737-97-006.

2 Estación Experimental Alfredo Volio Mata. Facultad de Agronomía. Universidad de Costa Rica.
} 
Posteriormente, la evaluación bromatológica y el aprovechamiento animal mostraron su baja calidad (Hernández, 1989). Reaparece a principios de la década del 90, un interés marcado por el sorgo negro forrajero, particularmente en zonas de altura media y baja. La investigación sobre el potencial para la producción animal de esta especie es inexistente en el país. Los productores de Cartago y de San Carlos señalan que los animales tienen altos consumos de forraje fresco o ensilado de sorgo negro y que los rendimientos de leche son similares a los obtenidos con otras especies forrajeras de corte. Su fenología es muy diferente a la de pastos perennes de corte y su estudio debe contribuir a determinar el manejo y aprovechamiento óptimo. Con este propósito se planteó el presente trabajo, el cual tiene por objetivo determinar el desarrollo fenológico de la planta y su calidad nutricional en las diferentes etapas de crecimiento.

\section{MATERIALES Y MÉTODOS}

El experimento se llevó a cabo en la Estación Experimental "Alfredo Volio Mata" de la Universidad de Costa Rica. La estación se ubica a 1542 msnm, con una precipitación media anual de $2050 \mathrm{~mm}$, distribuida en los meses de mayo a noviembre. La temperatura media es de $19,5^{\circ} \mathrm{C}$ y la humedad relativa media es de $84 \%$. El suelo es de origen volcánico, clasificado como Typic Distrandepts (Vásquez, 1982). Se caracteriza por una profundidad media, con buen drenaje natural y una fertilidad media. El terreno empleado tiene un $\mathrm{pH}$ de 6,0. La zona se tipifica ecológicamente como bosque húmedo montano bajo (Tosi, 1970; citado por Vásquez, 1982).

Se preparó una hectárea de terreno, arada y rastreada. Se fertilizó con $386 \mathrm{~kg}$ de la fórmula $\left(\mathrm{N}_{2}-\mathrm{P}_{2} \mathrm{O}_{5}-\mathrm{K}_{2} \mathrm{O}\right)$ 10-30-10. Se volvió a rastrear y se surcó a una distancia de $70 \mathrm{~cm}$. La siembra se hizo con $18 \mathrm{~kg}$ de semilla de sorgo negro forrajero ( $88 \%$ semilla pura germinable). La semilla fue mezclada con tierra seca fina, en una proporción de 1:1 $\mathrm{v} / \mathrm{v}$, distribuida manualmente a chorro continuo. A los 24 días de edad se realizó el primer muestreo de plantas y los siguientes se efectuaron cada 14 días, hasta completar 150 días de edad. A los 40 días de la siembra se aplicaron $45,5 \mathrm{~kg}$ de nitrógeno en forma de nitrato de amonio. Los sitios de muestreos se realizaron al azar, recolectando 10 metros lineales en el surco previamente seleccionado. Se tomaron dos muestras de cinco metros cada una. La primera muestra se empleó para estimar la producción de biomasa, separando tallos, hojas y panojas, cortadas las plantas a tres centímetros sobre el nivel del suelo. Las diferentes partes de la planta fueron pesadas y secadas en un horno a $60^{\circ} \mathrm{C}$ durante 48 horas, hasta alcanzar un peso constante. Se molieron y se procedió a determinar el contenido de materia seca en una estufa a $105^{\circ} \mathrm{C}$, la proteína cruda por el método de Kjeldall y la cenizas totales (AOCA, 1980). La fibra neutro detergente (FND), la fibra ácido detergente (FAD), la lignina fueron analizadas por el método descrito por Goering y Van Soest (1970). Los valores de hemicelulosa y celulosa se obtuvieron por diferencia de las fracciones correspondientes. En la segunda muestra, las plantas se extrajeron completamente, separando las raíces, tallos, hojas y panojas. Se midió el volumen radical, así como el largo y grosor de los tallos en la parte basal y apical.

\section{RESULTADOS}

La producción de biomasa verde y seca, en tallos, hojas, panoja y total, se midió en las plantas de sorgo negro forrajero, a diferentes edades de crecimiento, las cuales se presentan en el Cuadro 1. En la Figura 1 se observa la curva de producción total de materia seca cosechada, así como el desarrollo progresivo de las partes componentes de la planta conforme aumenta la edad. Durante los primeros 52 días de crecimiento, la producción de hojas fue mayor que la del tallo. Se estimó que a los 57 días, el rendimiento de materia seca fue de $1395 \mathrm{~kg} / \mathrm{ha}$, compuesto en un $50 \%$ por hojas y otro $50 \%$ por tallos (relación hoja:tallo de 1:1). Posterior a esta edad, el rendimiento del cultivo se incrementó con un mayor aporte de los tallos. A partir de los 66 días, la relación hoja:tallo fue de 0,41 y disminuyó hasta 0,15 a los 150 días (Cuadro 2). La aparición de la panoja se inició alrededor de los 94 días, con un aporte inicial de $50 \mathrm{~kg} / \mathrm{ha}$ de materia seca y de $2588 \mathrm{~kg} / \mathrm{ha}$ a los 150 días.

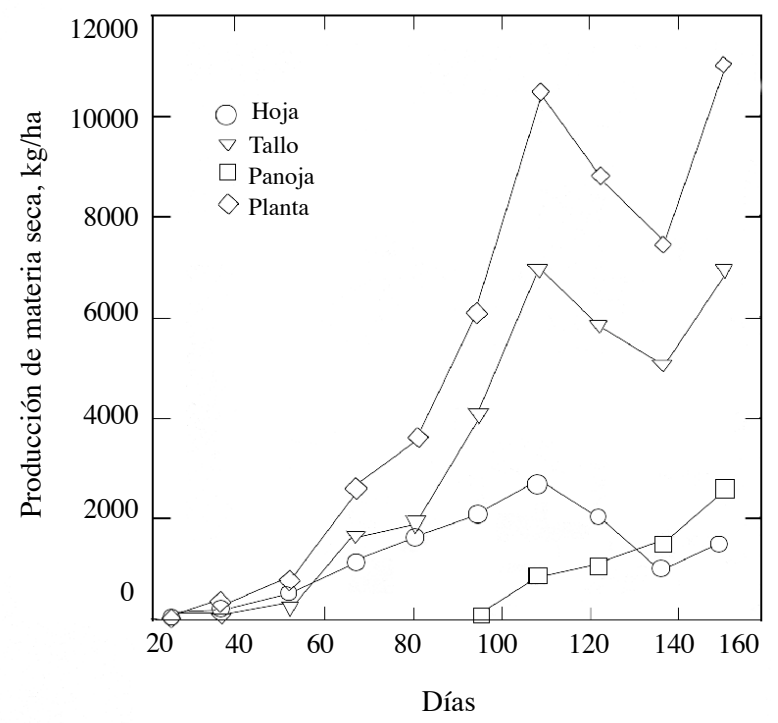

Figura 1. Producción de materia seca en la planta de sorgo negro forrajero a través de las edades de crecimiento. Est. Exp. Alfredo Volio M. UCR. 
Cuadro 1. Producción de materia verde y seca de la planta entera de sorgo negro forrajero y cada una de sus partes. Estación Alfredo Volio M. UCR.

\begin{tabular}{|c|c|c|c|c|c|c|c|c|}
\hline \multicolumn{5}{|c|}{ Materia fresca } & \multicolumn{4}{|c|}{ Materia $\underline{\text { Seca }}$} \\
\hline $\begin{array}{l}\text { edad } \\
\text { (días) }\end{array}$ & $\begin{array}{c}\text { hoja } \\
\text { (kg/ha) }\end{array}$ & $\begin{array}{l}\text { tallo } \\
(\mathrm{kg} / \mathrm{ha})\end{array}$ & $\begin{array}{c}\text { panoja } \\
\text { (kg/ha) }\end{array}$ & $\begin{array}{l}\text { total } \\
(\mathrm{kg} / \mathrm{ha})\end{array}$ & $\begin{array}{l}\text { hoja } \\
\text { (kg/ha) }\end{array}$ & $\begin{array}{l}\text { tallo } \\
(\mathrm{kg} / \mathrm{ha})\end{array}$ & $\begin{array}{c}\text { panoja } \\
(\mathrm{kg} / \mathrm{ha})\end{array}$ & $\begin{array}{l}\text { total } \\
(\mathrm{kg} / \mathrm{ha})\end{array}$ \\
\hline 24 & 205 & & & 205 & 37 & & 37 & \\
\hline 38 & 2350 & 1245 & & 3595 & 285 & 70 & & 355 \\
\hline 52 & 2875 & 2225 & & 5100 & 495 & 200 & & 695 \\
\hline 66 & 6350 & 15500 & & 21850 & 1080 & 1575 & & 2655 \\
\hline 80 & 7500 & 18275 & & 25775 & 1645 & 1875 & & 3520 \\
\hline 94 & 6590 & 23550 & 450 & 30590 & 2000 & 4000 & 50 & 6050 \\
\hline 108 & 8450 & 26950 & 2850 & 38250 & 2750 & 6900 & 800 & 10450 \\
\hline 122 & 7230 & 22250 & 3750 & 33230 & 1930 & 5807 & 1045 & 8782 \\
\hline 136 & 2570 & 20350 & 3650 & 26570 & 930 & 5006 & 1445 & 7381 \\
\hline 150 & 3700 & 25250 & 5740 & 34690 & 1495 & 6893 & 2588 & 10976 \\
\hline
\end{tabular}

La Figura 1 muestra que la mayor producción de forraje se alcanzó alrededor de dos semanas posteriores a la emergencia de la panoja. Después de este momento (108 días), se observa un descenso en el rendimiento de hojas y tallos, a pesar del aumento de materia seca por el desarrollo de la panoja. En el Cuadro 3, se presenta la contribución porcental de biomasa de las diferentes partes de la planta, incluyendo la raíz y en el Cuadro 4, se muestran los valores medios de la altura y grosor de los tallos, así como el volumen radical , observados durante las diferentes edades de crecimiento.

Cuadro 2. Relación hoja:tallo en diferentes edades de crecimiento de sorgo negro forrajero. Estación Experimenal Alfredo Volio Mata. UCR

\begin{tabular}{ccc}
\hline $\begin{array}{c}\text { Edad } \\
\text { (días) }\end{array}$ & $\begin{array}{c}\text { Relación } \\
\text { hoja:tallo } \\
\text { en base verde }\end{array}$ & $\begin{array}{c}\text { Relación } \\
\text { hoja:tallo } \\
\text { en base seca }\end{array}$ \\
\hline 24 & & \\
38 & 1,89 & 4,07 \\
52 & 1,29 & 2,48 \\
66 & 0,41 & 0,69 \\
80 & 0,41 & 0,88 \\
94 & 0,28 & 0,50 \\
108 & 0,31 & 0,40 \\
122 & 0,32 & 0,33 \\
136 & 0,13 & 0,19 \\
150 & 0,15 & 0,22 \\
\hline
\end{tabular}

En el Cuadro 5 se presenta la composición nutricional de las partes de la planta de sorgo negro forrajero, en diferentes edades de crecimiento. La concentración de materia seca en la hoja fue mayor que en el tallo desde edades tempranas hasta los 136 días de creci- miento. A los 150 días el contenido de materia seca en el tallo fue superior al hallado en la hoja. En la planta total, la concentración de materia seca fue aumentando de $10 \%$ a los 38 días hasta $38 \%$ a los 150 días. El contenido de proteína cruda en la hoja fue siempre superior al mostrado en el tallo. El contenido proteico disminuyó progresivamente en la hoja de casi 28 a $16 \%$ conforme aumentó la edad de 38 a 150 días. En el mismo período, el contenido de proteína en el tallo disminuyó de 18 a $5 \%$ y en la planta total, la concentración pasó de 26 a $8 \%$, incluyendo la panoja, la cual presentó un $16 \%$ a los 108 días y disminuyó a un $10 \%$ a 150 días. El contenido de fibra neutro detergente en hojas y tallos fue inferior a $60 \%$ en los primeros dos meses de crecimiento. La hoja no presentó valores superiores a $70 \%$ durante el restante periodo de crecimiento, mientras que el tallo alcanzó ese nivel a los 80 días y posteriormente fue incrementando la fracción fibrosa hasta alcanzar $80 \%$ a los 150 días. La panoja mostró un contenido de fibra neutro detergente de $57 \%$ al iniciar su emergencia (108días) e incrementó la concentración a un $65 \%$ a los 150 días. La planta completa mostró valores de $50 \%$ de pared celular al inicio del crecimiento y de $75 \%$ al final. Los componentes de la fibra neutro detergente: hemicelulosa, celulosa y lignina, muestran en hojas y tallos una concentración creciente conforme aumenta la edad de la planta de sorgo negro forrajero. La planta total tuvo valores de 21, 27 y $3 \%$ de hemicelulosa, celulosa y lignina a los 38 días y 28,39 y $7,5 \%$ a los 150 días. En este periodo, el cambio de concentración de hemicelulosa fue bajo, en la celulosa fue medio y muy alto en la lignina. En el Cuadro 5, se observa el contenido de cenizas totales hallado en hojas, tallos y la panoja, así como los valores en la planta completa a través del periodo de crecimiento. 
Cuadro 3. Distribución porcentual de la biomasa en las diferentes partes de la planta de sorgo. Estación Exp. Alfredo Volio Mata. UCR.

\begin{tabular}{|c|c|c|c|c|c|c|c|c|c|c|}
\hline \multicolumn{6}{|c|}{ Materia verde } & \multicolumn{5}{|c|}{ Materia seca } \\
\hline $\begin{array}{l}\text { Edad } \\
\text { días }\end{array}$ & $\begin{array}{c}\text { Hoja } \\
\%\end{array}$ & $\begin{array}{c}\text { Tallo } \\
\%\end{array}$ & $\begin{array}{c}\text { Raíz } \\
\%\end{array}$ & $\begin{array}{c}\text { Panoja } \\
\%\end{array}$ & $\begin{array}{c}\text { Total } \\
\%\end{array}$ & $\begin{array}{c}\text { Hoja } \\
\%\end{array}$ & $\begin{array}{c}\text { Tallo } \\
\%\end{array}$ & $\begin{array}{c}\text { Raíz } \\
\%\end{array}$ & $\begin{array}{c}\text { Panoja } \\
\%\end{array}$ & $\begin{array}{c}\text { Total } \\
\%\end{array}$ \\
\hline 24 & 43,71 & 36,47 & 19,82 & & 100 & 53,8 & 26,8 & 19,4 & & 100 \\
\hline 38 & 32,93 & 40,24 & 26,83 & & 100 & 41,7 & 33,3 & 25 & & 100 \\
\hline 52 & 45,23 & 24,07 & 30,71 & & 100 & 44,7 & 23,4 & 31,9100 & & \\
\hline 66 & 24,05 & 61,53 & 14,43 & & 100 & 35,7 & 45,9 & 18,4 & & 100 \\
\hline 80 & 15,69 & 68,79 & 15,52 & & 100 & 26,4 & 54,4 & 19,2 & & 100 \\
\hline 94 & 14,11 & 69,34 & 13,75 & 2,80 & 100 & 18,3 & 64 & 15,2 & 2,4 & 100 \\
\hline 108 & 13,27 & 67,35 & 14,26 & 5,11 & 100 & 17,7 & 62,2 & 13,1 & 7,1 & 100 \\
\hline 122 & 13,55 & 60,03 & 12,35 & 14,07 & 100 & 13,9 & 60,4 & 10,6 & 15,1 & 100 \\
\hline 136 & 9,19 & 65,88 & 13,65 & 11,28 & 100 & 11,9 & 57,8 & 14,5 & 15,9 & 100 \\
\hline 150 & 9,83 & 58,19 & 20 & 11,98 & 100 & 12,9 & 50,5 & 19,7 & 17,2 & 100 \\
\hline
\end{tabular}

\section{DISCUSIÓN}

El sorgo se cultiva generalmente bajo condiciones de climas secos y calientes. Comparado con el maíz, el sorgo tiene un sistema radicular más fibroso y ramificado, lo que permite penetrar un mayor volumen de suelo para obtener la humedad (Leland, R.H. 1982). El sorgo forrajero se adapta bien desde el nivel de mar hasta los 1900 m.s.n.m y su crecimiento se limita a temperaturas inferiores a los $13^{\circ} \mathrm{C}$ (Carrera, M., 1965). Es un cultivo creciente entre los productores de leche y requiere atención experimental en las zonas tanto de altura como de bajura en Mesoamérica. En el presente estudio se cuantificó, a diferentes edades, la producción de materia verde y materia seca a través del crecimiento de la planta de sorgo negro forrajero para uso en la alimentación de animales rumiantes. El presente trabajo muestra el rendimiento total del cultivo, en diferentes edades de crecimiento, y su fraccionamiento en tallos, hojas y panojas, lo que permite conocer separadamente la contribución de las partes de la planta e individualizar la composición nutricional de cada

Cuadro 4. Altura, grosor basal y apical de los tallos y volumen radical durante las diferentes edades de crecimiento.

\begin{tabular}{ccccc}
\hline $\begin{array}{c}\text { Edad } \\
\text { días }\end{array}$ & $\begin{array}{c}\text { Altura } \\
\text { cm }\end{array}$ & $\begin{array}{c}\text { Grosor } \\
\text { basal } \\
\text { mm }\end{array}$ & $\begin{array}{c}\text { Grosor } \\
\text { apical } \\
\text { mm }\end{array}$ & $\begin{array}{c}\text { Volumen } \\
\text { radical } \\
\text { cc }\end{array}$ \\
\hline 24 & 7,84 & 3,18 & 3,05 & 7 \\
38 & 17,20 & 5,34 & 4,27 & 18 \\
52 & 28,35 & 10,40 & 6,22 & 120 \\
66 & 61,97 & 10,83 & 6,75 & 150 \\
80 & 149,90 & 10,68 & 5,78 & 205 \\
94 & 229,13 & 11,44 & 4,69 & 100 \\
108 & 287,40 & 13,20 & 3,70 & 115 \\
122 & 240,00 & 10,30 & 3,60 & 150 \\
136 & 267,83 & 10,50 & 5,00 & 240 \\
150 & 274,20 & 10,50 & 5,10 & 200 \\
\hline
\end{tabular}

estructura vegetal. Tomando en cuenta el régimen lluvioso de Costa Rica, el cultivo de sorgo negro forrajero podría cosecharse de cuatro a cinco veces al año, empleando las edades de corte recomendadas por Hernández, 1989 y Corrales, 1986. La producción de biomasa observada en el presente experimento muestra que a partir de 66 días de crecimiento se obtuvieron rendimiento superiores a $20 \mathrm{t} / \mathrm{h}$ a de forraje verde, equivalente a 2,6 t/ha de forraje seco. A los 108 días el rendimiento creció a 38 t/ha de forraje verde y a 10,4 t/ha de forraje seco. En ambos casos se observa que el mayor contribuyente al tonelaje lo constituye el tallo. Antes de los 57 días, la producción de hojas en mayor que la de tallo, y luego esta relación se invierte, siendo la producción de tallos predominante. En el Cuadro 5 se observa que a partir de los 65 días de crecimiento la composición química de la planta entera es buena y a partir de los 85 días decrece su calidad, especialmente el contenido de proteína cruda en el tallo. Así mismo comienza a incrementarse el contenido de lignina en el tallo, a pesar de observarse un $15 \%$ de materia seca en la planta total. En términos generales las hojas presentaron un mayor contenido de materia seca y de proteína cruda que los tallos. Los contenidos de proteína cruda encontrados en este experimento fueron superiores a los informados por Alfaro, 1988 y por Villegas, 1990.

\section{CONCLUSIONES Y RECOMENDACIONES}

En la zona de altura de la Meseta Central, donde se llevó a cabo el experimento, se obtuvo un buen rendimiento de materia seca en el sorgo negro forrajero, tomando en cuenta que es producto de primera cosecha. Se estimó que hasta los 57 días de crecimiento, la planta está formada por una mayor proporción de tallos. El crecimiento de tallos es muy acelerado, a los 66 días la cantidad de materia seca en tallos es más de 1,5 veces 
Cuadro 5. Contenido de materia seca del sorgo negro forrajero y su composición química, en diferentes edades de crecimiento.

\begin{tabular}{|c|c|c|c|c|c|c|c|c|c|}
\hline $\begin{array}{l}\text { Parte de } \\
\text { la planta }\end{array}$ & $\begin{array}{l}\text { Edad } \\
\text { días }\end{array}$ & $\begin{array}{c}\text { Materia } \\
\text { seca } \%\end{array}$ & $\begin{array}{c}\text { Proteína } \\
\text { cruda }\end{array}$ & $\begin{array}{c}\text { FND } \\
\%\end{array}$ & $\begin{array}{c}\text { FAD } \\
\%\end{array}$ & $\begin{array}{c}\text { Hemicelulosa } \\
\%\end{array}$ & $\begin{array}{c}\text { Celulosa } \\
\%\end{array}$ & $\underset{\%}{\text { Lignina }}$ & $\begin{array}{c}\text { Cenizas } \\
\%\end{array}$ \\
\hline \multirow[t]{9}{*}{ Hoja } & 38 & 11,53 & 27,70 & 49,65 & 29,34 & 20,31 & 26,28 & 3,06 & 12,27 \\
\hline & 52 & 15,88 & 24,44 & 55,89 & 28,46 & 29,43 & 25,64 & 2,86 & 10,84 \\
\hline & 66 & 15,99 & 24,64 & 61,75 & 34,74 & 27,01 & 31,15 & 3,59 & 10,99 \\
\hline & 80 & 20,20 & 19,94 & 66,44 & 38,51 & 27,93 & 32,53 & 5,98 & 12,53 \\
\hline & 94 & 26,90 & 21,20 & 60,24 & 37,11 & 23,13 & 33,70 & 3,41 & 10,60 \\
\hline & 108 & 29,95 & 20,17 & 61,50 & 38,20 & 23,30 & 32,85 & 5,35 & 10,76 \\
\hline & 122 & 25,11 & 18,09 & 65,02 & 39,36 & 25,66 & 33,03 & 6,33 & 11,17 \\
\hline & 136 & 32,71 & 17,46 & 68,51 & 35,78 & 32,73 & 30,63 & 5,15 & 9,16 \\
\hline & 150 & 36,68 & 15,98 & 69,16 & 37,35 & 31,81 & 30,99 & 6,36 & 8,50 \\
\hline \multirow[t]{9}{*}{ Tallo } & 38 & 5,86 & 18,93 & 54,36 & 31,09 & 23,27 & 28,50 & 2,59 & 19,73 \\
\hline & 52 & 9,58 & 15,97 & 58,33 & 31,42 & 26,91 & 28,61 & 2,81 & 16,52 \\
\hline & 66 & 9,44 & 13,10 & 64,11 & 40,83 & 23,28 & 37,37 & 3,06 & 15,67 \\
\hline & 80 & 9,88 & 8,62 & 69,33 & 48,08 & 21,25 & 44,02 & 4,06 & 15,87 \\
\hline & 94 & 16,08 & 7,39 & 74,93 & 54,07 & 20,86 & 48,03 & 6,04 & 11,74 \\
\hline & 108 & 12,25 & 5,44 & 72,46 & 47,73 & 24,73 & 41,25 & 6,48 & 8,81 \\
\hline & 122 & 23,85 & 4,87 & 77,97 & 54,18 & 23,79 & 46,44 & 7,74 & 7,38 \\
\hline & 136 & 22,23 & 4,80 & 81,60 & 57,04 & 24,56 & 49,61 & 7,43 & 7,44 \\
\hline & 150 & 41,18 & 5,24 & 79,97 & 53,91 & 26,06 & 46,68 & 7,23 & 8,07 \\
\hline \multirow[t]{4}{*}{ Panoja } & 108 & 27,25 & 15,93 & 56,75 & 31,97 & 24,78 & 24,76 & 7,21 & 5,53 \\
\hline & 122 & 24,82 & 12,64 & 69,61 & 41,75 & 27,86 & 34,74 & 7,01 & 13,03 \\
\hline & 136 & 35,66 & 11,44 & 72,98 & 37,97 & 35,01 & 30,24 & 7,73 & 6,44 \\
\hline & 150 & 31,12 & 10,30 & 65,33 & 33,17 & 32,16 & 24,24 & 8,93 & 6,91 \\
\hline \multirow[t]{9}{*}{ Total } & 38 & 10,41 & 25,97 & 50,58 & 26,69 & 20,89 & 26,72 & 2,97 & 13,74 \\
\hline & 52 & 14,07 & 22,00 & 56,59 & 29,31 & 28,70 & 26,49 & 2,82 & 12,47 \\
\hline & 66 & 12,10 & 17,79 & 63,15 & 38,35 & 24,80 & 34,84 & 3,28 & 13,77 \\
\hline & 80 & 14,70 & 13,91 & 67,98 & 43,61 & 24,37 & 38,65 & 4,49 & 14,31 \\
\hline & 94 & 19,69 & 11,99 & 70,03 & 48,42 & 21,62 & 43,25 & 5,16 & 11,36 \\
\hline & 108 & 18,06 & 10,12 & 68,37 & 44,02 & 24,36 & 37,78 & 6,24 & 9,07 \\
\hline & 122 & 24,24 & 8,70 & 74,13 & 49,44 & 24,69 & 42,10 & 7,34 & 8,89 \\
\hline & 136 & 26,18 & 7,70 & 78,26 & 50,63 & 27,64 & 43,43 & 7,20 & 7,46 \\
\hline & 150 & 38,20 & 7,90 & 75,05 & 46,76 & 28,28 & 39,25 & 7,51 & 7,86 \\
\hline
\end{tabular}

el de hoja, proporción que continúa en el siguiente mes. Entre dos y tres meses de crecimiento es la edad apropiada de cosecha de forraje para la alimentación animal, debido al contenido de materia seca y proteína cruda.

\section{LITERATURA CITADA}

ALFARO, O.L. 1988. Evaluación de la producción y calidad del sorgo negro forrajero (Sorgum almum) a través de diferentes distancias de siembra, densidades de siembra y niveles de fertilización nitrogenada. Tesis Ing. Agrónomo. Escuela de Zootecnia, Universidad de Costa Rica. 107 p.

A.OA.C. 1980. Methods of analysis. Ed. 13 Washington D.C. E.U.A. Association of Official analysis chemistry.

CARRERA, M. 1965. Estudio comparativo de rendimientos de sorgos forrajeros (Sorghum vulgare Pers) en la zona Pacífico Norte. Tesis Ing. Agr. Facultad de Agronomía, Universidad de Costa Rica. 105 p.
CORRALES, J.C. 1986. Efecto de la densidad y distancia de siembra y la fertilzación nitrogenada sobre la producción de biomasa y la calidad del sorgo negro forrajero (Sorghum almum). Tesis Ing. Agron. Escuela de Zootecnia. Universidad de Costa Rica. 173 p.

GOERING, H.K.; VAN SOEST, P.J. 1970. Forage fiber analysis (Apparatus, reagents, procedures and some applications). Agricultural Handbook $N^{\circ} 379$. ARS-USDA. Washington, D.C.

HERNANDEZ, X.M. 1989. Comportamiento agronómico de tres forrajes de corte durante la época seca en Tilarán. Tesis de ing. Agron. Sede regional de Guanacaste, Universidad de Costa Rica. 126 p.

HERNANDEZ,H.E. 1986. Fertilización nitrogenada y edad de corte para sorgo forrajero (Sorghum almum). Tesis de Ing. Agron. Escuela de Zootecnia, Universidad de Costa Rica. 145p.

JIMÉNEZ, C.A. 1995. Degradabilidad ruminal del sorgo negro forrajero (Sorghum almum), tesis de Maestría en 
nutricion animal. Programa en Ciencias Agrícolas y Recursos Naturales, Universidad de Costa Rica, 61 p.

LELAND, R.H. 1982. El sorgo. Guía para su mejoramiento genético. Universidad Autónoma Chapingo. Grupo Editorial Gaceta, S.A. 425p.

STEVENS, G.R. 1975. Forage sorghums on the Darling Downs. Queensland Agricultural Journal 19:721-728.

SIMÓN, B.K. 1979. Naturalized fodder sorghum in Queensland and their role in shattering grain sorghum. Queen- lands Journal of Agricultural and Animal Sciences 36:71-86.

VÁSQUEZ, A. 1982. Estudio detallado de los suelos de la Estación Experimental de Ganado Lechero El Alto. Escuela de Fitotecnia, Facultad de Agronomía, Universidad de Costa Rica. p.36

VILLEGAS, O. 1990. Producción y valor nutritivo de sorgos forrajeros y sus ensilados a diferentes edades de cosecha. Tesis de Ing. Agron. Sede Regional de Guanacaste, Universidad de Costa Rica. 84 p. 